\title{
RECUPERAÇÃO ESTRUTURAL EM PILARES DE ARGILA SILTOSA: O CASO DA FUNDAÇÃO DA MEMÓRIA REPUBLICANA BRASILEIRA (CONVENTO DAS MERCÊS, SÃO LUÍS-MA)
}

\author{
AMORIM, FABRÍCIO \\ Discente \\ IPOG \\ Maranhão; Brasil \\ fabricio.amorim2006@hotmail.com
}

\author{
MARTINS, RAFAEL \\ Docente \\ IPOG \\ Distrito Federal; Brasil \\ rafael.concreta@gmail.com
}

\section{RESUMO}

A literatura técnica traz um elevado nível de complexidade em intervenções de estruturas qualificadas como Patrimônio Histórico. Seja por conta de limitações para não se descaracterizar a história, ou, ainda, devido a uma expressiva escassez documental, tem-se, em tais cenários, um processo praticamente artesanal para o levantamento de dados que fundamentem as intervenções que o tempo demanda. No presente caso, expõe-se toda a sequência metodológica que pautou os procedimentos de reforço dos pilares do claustro da Fundação da Memória Republicana Brasileira (mais de 200 anos). Nesse processo, foram empregadas técnicas para coleta de dados estruturais, geotécnicos, hidrológicos e topográficos, além de minuciosas inspeções visuais. Com o intuito de contribuir para preservação, conservação e recuperação estrutural dos pilares da Fundação da Memória Republicana Brasileira (Convento das Mercês), foram discutidas no decorrer deste estudo de caso, patologias, suas manifestações e possíveis causas, assim como, formas de reestruturação dos pilares escorados.

Como resultado, optou-se, de forma fundamentada, por um procedimento de recuperação que conjugasse o preenchimento com groute e o encamisamento com chapas metálicas, entre outros detalhes; arranjo esse que permitirá a extensão da vida útil da edificação, que porta enorme valor social, e está exposta a um ambiente agressivo.

Palavras-chave: Recuperação estrutural. Argila siltosa. Patologia das construções.

\section{ABSTRACT}

A literatura técnica traz um elevado nível de complexidade em intervenções de estruturas qualificadas como Patrimônio Histórico. Seja por conta de limitações para não se descaracterizar a história, ou, ainda, devido a uma expressiva escassez documental, tem-se, em tais cenários, um processo praticamente artesanal para o levantamento de dados que fundamentem as intervenções que o tempo demanda. No presente caso, expõe-se toda a sequência metodológica que pautou os procedimentos de reforço dos pilares do claustro da Fundação da Memória Republicana Brasileira (mais de 200 anos). Nesse processo, foram empregadas técnicas para coleta de dados estruturais, geotécnicos, hidrológicos e topográficos, além de minuciosas inspeções visuais. Com o intuito de contribuir para preservação, conservação e recuperação estrutural dos pilares da Fundação da Memória Republicana Brasileira (Convento das Mercês), foram discutidas no decorrer deste estudo de caso, patologias, suas manifestações e possíveis causas, assim como, formas de reestruturação dos pilares escorados.

Como resultado, optou-se, de forma fundamentada, por um procedimento de recuperação que conjugasse o preenchimento com groute e o encamisamento com chapas metálicas, entre outros detalhes; arranjo esse que permitirá a extensão da vida útil da edificação, que porta enorme valor social, e está exposta a um ambiente agressivo.

Keywords: Structural recovery. Silt clay. Pathology of buildings. 


\section{INTRODUÇÃO}

O homem vem buscando, a cada dia, novos conhecimentos sobre construção e recuperação de edifícios, desde o início da civilização, com o objetivo de melhor atender as suas necessidades. Nesse contexto, as antigas edificações, tombadas pelo Patrimônio Histórico, trazem desafios adicionais. No caso concreto, ao se estudar as condições inerentes ao reforço de pilares, sabe-se da premência de o projetista detalhar a intervenção a fim de garantir o uso seguro (Pádua, 2012). Por outro lado, há que se reconhecer vários cenários em que o empirismo ainda prevalece, ante a escassez de soluções cientificamente embasadas quanto ao reforço de construções centenárias.

O bicentenário edifício do Convento das Mercês, feito de argila siltosa com pedra de mão, lidou com vibrações ao longo de vários anos, notadamente, por conta de eventos culturais, da circulação de veículos no entorno e por fatores climáticos, trazendo como efeito os descolamentos de pedras lamelares e trincas nos revestimentos.

Ante as intrínsecas limitações de intervenção e para não descaracterizar a construção, o presente trabalho pretende responder ao seguinte questionamento: de que forma o grauteamento e o encamisamento podem ser utilizados na recuperação estrutural em pilares de argila siltosa que sofreram desprendimento de argamassa na Fundação da Memória Republicana Brasileira?

Este estudo tem por objetivo geral apresentar elucidações para a recuperação estrutural dos pilares envoltórios do claustro da Fundação da Memória Republicana Brasileira (Convento das Mercês) e, como específicos: identificar as causas e consequências das manifestações patológicas presentes na estrutura do Convento; agregar informações coletadas por meio de inspeções visuais, ensaios e prospecções; equacionar as informações básicas e indicações de detalhes executivos para recuperação do sistema estrutural; descrever os procedimentos de recuperação a serem aplicados; apresentar mecanismos de proteção visando evitar manifestações patológicas na edificação.

\section{DESENVOLVIMENTO}

\subsection{Patrimônio histórico e cultural}

A terminologia 'patrimônio' possui conotação jurídica e origina-se do latim patrimonium, que quer dizer herança paterna, legado. O entendimento atual sobre patrimônio histórico foi definido a partir do Século XIX, quando a história sofreu interferência do movimento positivista, passando a ter status de ciência (Gandelman, 2006).

A NBR 14653-7 (ABTN, 2009, p.2) define patrimônio histórico e artístico, de modo a ficar claro ser este o caso do Convento das Mercês.

Bem, móvel ou imóvel, tomado individualmente ou em conjunto, portador de referência à identidade, à ação, à memória dos diferentes grupos formadores da sociedade brasileira, nos quais se incluem: obras, objetos, documentos, edificações, demais espaços destinados às manifestações artístico-culturais e os conjuntos urbanos e sítios de valor histórico, paisagístico, artístico, arqueológico, paleontológico e científico, cuja conservação seja do interesse público, quer por sua vinculação a fatos memoráveis da história, quer por sua notória expressão artística ou arquitetônica, quer por sua antiguidade, quer por sua importância arqueológica, antropológica ou científica.

\subsection{Fundação da Memória Republicana Brasileira}

A primeira edificação do Convento deu-se por volta de 1600, ocasião em que foram empregadas argila e pedras lamelares. Em 1989, o prédio do antigo Convento das Mercês foi incluído no Projeto Reviver, por iniciativa do Governo do Estado, que se propunha a recuperar o acervo arquitetônico e paisagístico do Centro Histórico de São Luís, com o objetivo de restaurar esse convento, que é detentor de um rico acervo museológico, bibliográfico e palco de eventos e mostras culturais. 
Antes dessa restauração, o edifício abrigava o Quartel do Corpo de Segurança (Companhia de Bombeiros), que lhe infligiu significativas intervenções, alterando seu interior e suas fachadas. Hoje nesse prédio, funcionam a Fundação da Memória Republicana Brasileira (FMRB), o Memorial José Sarney, o Centro Modelador de Pesquisa da História Republicana e o Instituto da Amizade dos Povos de Língua Portuguesa.

O mesmo vem sofrendo, por décadas, com a ação do tempo, deteriorando-se ao ponto de sofrer ameaça de desabamento devido as intempéries e reverberação. Portanto, a recuperação e a preservação desse edifício são de suma importância diante do grande significado histórico para São Luís, capital do Estado do Maranhão (Meireles, 1991).

\subsection{Anomalias}

De acordo com os dicionários, patologia é a parte da Medicina que estuda as doenças. Tal conceito foi importado ao ramo da Engenharia, naquilo que a literatura habituou-se a nomear como Engenharia Diagnóstica (Gomide, 2009).

Considera-se patologia, diferentemente de envelhecimento natural, qualquer fenômeno que, ocorrendo fora de um período previsível, afete o desempenho do prédio, seja ele no aspecto físico-econômico ou estético. Segundo Eldridge (1982), Ransom (1987) e Duarte (1988), as classificações dos fenômenos patológicos podem ser mostradas de distintas maneiras, dependendo da observação pretendida.

Devido a ação dos ventos, das chuvas, da luz, do calor, das emissões gasosas, das vibrações, variações térmicas e de umidade, a que os pilares do claustro ficam expostos, somados às vibrações e às cargas estáticas, têm-se condições de contorno favoráveis ao surgimento de manifestações patológicas (conforme a figura 1).

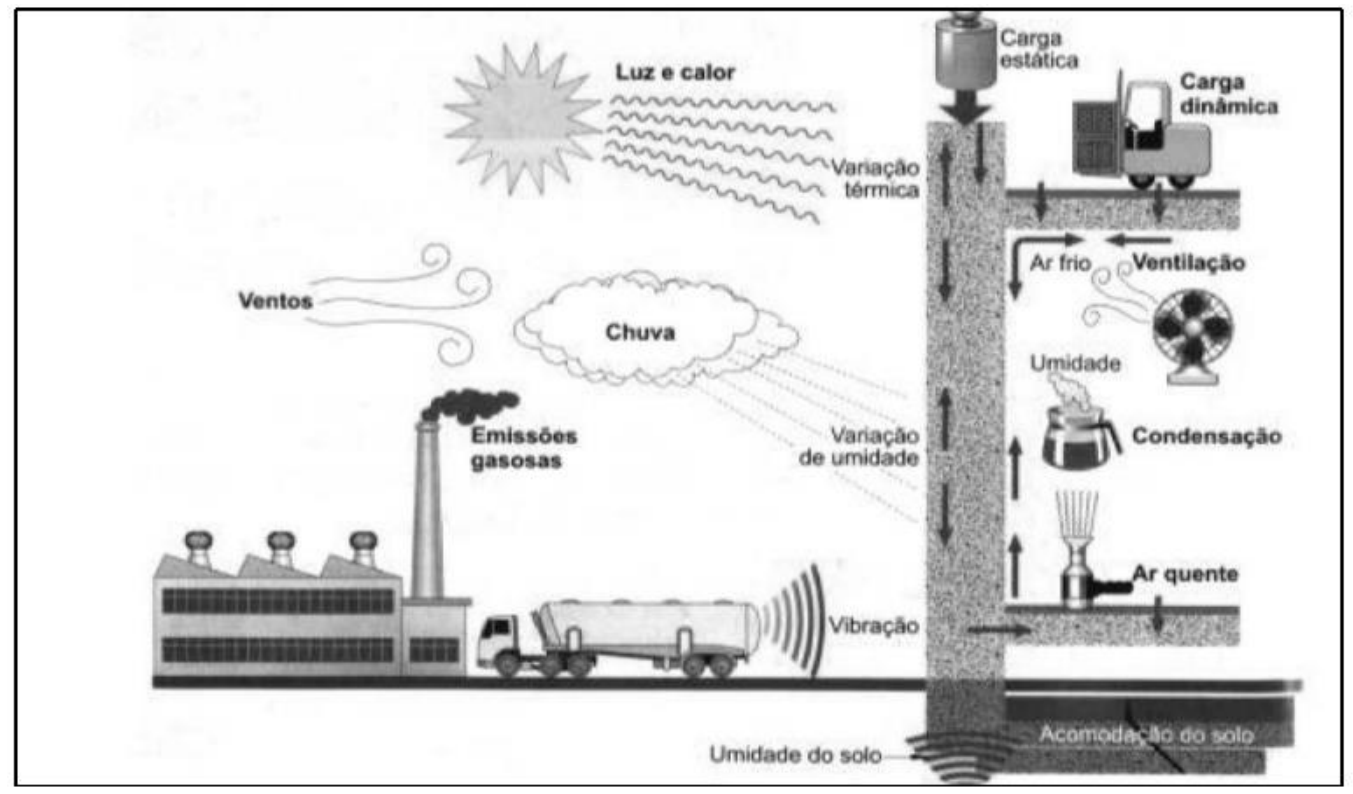

Figura 1 - Ações de intempéries

Fonte: Bonin et al. (1999).

\subsubsection{Origem das anomalias na edificação}

O imóvel, objeto do presente trabalho, apresentava anomalias que, se não tratadas, poderiam levar ao longo do tempo a um colapso progressivo da edificação. As anomalias encontradas no pátio central foram decorrentes da exposição a intempéries dos maciços de pedras argamassadas e arcos sem o devido tratamento. Não se observou, em nenhum ponto ou local dos materiais constituintes do núcleo das paredes, a aplicação de qualquer substância hidrofugante ou impermeabilizante. Segundo informações coletadas, as obras executadas entre 1987 e 1990, na cobertura com alteração das posições e das tesouras de sustentação do telhado, também contribuíram para a geração de novos esforços nas paredes, o que contribuiu com o surgimento de anomalias. 


\subsection{Desagregação/Perda de Material}

A ação das águas e vibrações ocasionaram a acelerada desagregação dos maciços. Com a perda de rigidez do maciço e falta de coesão entre os elementos que o constituem, comprometeu-se a resistência necessária aos esforços aplicados (carregamentos), acarretando nos efeitos de recalque nas paredes (ruptura característica por esmagamento). Ainda, por consequência da ação das intempéries e águas de lavagem, houve a retirada da camada de argamassa que atuava como proteção dos pilares (conforme a figura 2).

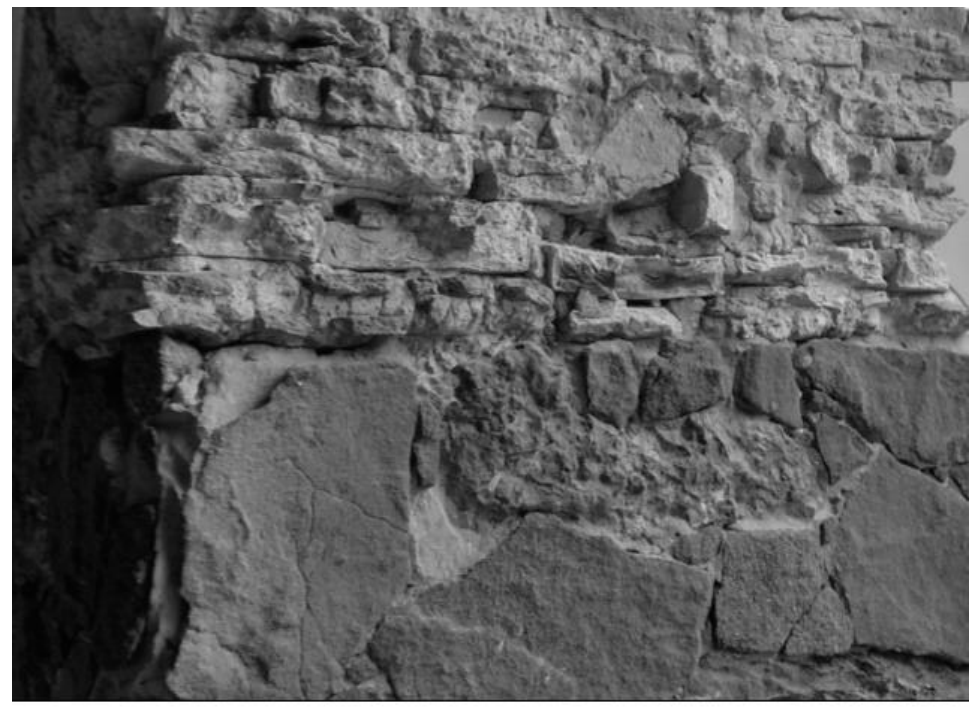

Figura 2 - Pilares em estágio de perda de pedras lamelares e argila siltosa Fonte: $\mathrm{O}$ autor (2020).

\subsubsection{Trincas e fissuras}

Lapa (2008), considera a trinca como a fratura linear existente no concreto. As trincas podem ser desenvolvidas de forma parcial ou completamente em toda profundidade de um elemento estrutural. Além disso, apesar de ausência de uma harmonização conceitual absoluta, dissemina-se que fissuras seriam aberturas de menor magnitude.

As fissuras podem ainda ocorrer por outras causas, como retração plástica, térmica ou devido a reações químicas internas do concreto nas primeiras idades, devendo ser evitadas ou limitadas por cuidados tecnológicos, especialmente na definição do traço e na cura do concreto, conforme demonstra a NBR 6118 (ABNT, 2014), em seu item 13.4.1.

As trincas e fissuras foram proporcionadas pela instabilidade do maciço e pela não utilização de material adequado para o revestimento da parede (conforme a figura 3 ).

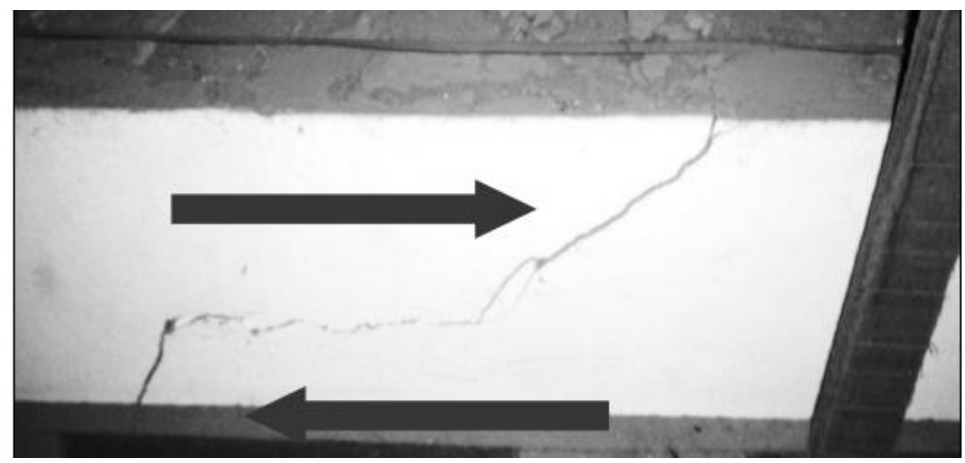

Figura 3 - Trincas decorrentes da instabilidade do maciço.

Fonte: O autor (2020). 


\section{PROSPECÇÃO ESTRUTURAL DA EDIFICAÇÃO}

Diante dos conceitos e da sintomatologia acima retratados, mostrou-se imprescindível partir para uma análise mais minudente, a qual subdividiu-se em aspectos: i) das fundações; ii) geotécnicos; iii) hidrológicos, e; iv) topográficos.

\subsection{Análise da Fundação}

Foram prospectadas as fundações de todos os pilares do claustro voltadas para o mar. No primeiro momento da visita, observou-se que cinco dos sete pilares do claustro estavam sob ação de escoramento. Considerando o estado de conservação dos pilares e, também, para a realização das prospecções, os escoramentos de alguma maneira deveriam ser retirados ou alterados de posição; desta forma, optou-se somente pela execução de uma janela de inspeção.

Cabe ressaltar que todos os pilares apresentaram a mesma secção do fuste e da fundação do subsolo, sem a existência de bloco de fundação. Entendeu-se, também, que o desconfinamento de todas as fundações somente para observação, sob atual estado, sem ações de pronto atendimento de intervenção, seria temerário e colocaria em risco os elementos construtivos.

Verificou-se a existência de fundação tipo alicerce em pedras argamassadas, estando as argamassas em médio estado de decomposição e sem coesão. Além disso, os pilares apresentavam-se secos, trazendo umidade apenas na seção sob o nível do piso, na região em contato com o solo.

Não foram detectados efeitos de recalque de fundações. Os pisos (térreo), nos entornos dos pilares, não apresentaram trincas nem mesmo fissuras, como também rebaixamentos ou desnivelamentos, indicando recalques ou afundamento de camadas de solo por arraste de partículas por ação de águas.

\subsection{Estudos geotécnicos}

A partir dos dados obtidos por meio de prospecção do solo, observou-se que o mesmo, onde se encontra a edificação, representa uma massa de aterro composta por duas camadas distintas, sendo a primeira e mais superficial de material arenoso (areia siltosa) com pedregulhos e espessura média de 2,50 metros; e abaixo, uma segunda de material argilosiltoso com pedregulhos e espessura média de 2,0 metros. As sondagens e o ensaio de percolação indicaram que o solo apresenta-se confinado, com estados de compactação variáveis pertinentes à época da execução das últimas obras realizadas e com nível de lençol freático bem abaixo da edificação, com cota aproximada de 5,0m de profundidade.

O solo superficial também apresenta resultados de percolação altos, o que mostra velocidade no escoamento das águas que nele infiltram, reforçando a importância de um sistema de drenagem adequada para o claustro.

\subsection{Estudos Hidrológicos}

O estudo hidrológico foi desenvolvido com a finalidade de serem avaliadas as circunstâncias climáticas, pluviométricas e hídricas na região em que se localiza a edificação em questão, para caso necessário possíveis intervenções.

\subsection{Levantamento Topográfico}

Esse levantamento foi realizado de acordo com as especificações do Termo de Referência, que trazia premissas para superar limitações verificadas in loco.

Valendo-se da metodologia adequada, foi deliberada a precisão do levantamento topográfico e depois disto, com a escala de representação e as técnicas utilizadas, se obteve a precisão na representação dos dados topográficos coletados em campo. Para complementação e verificações futuras foram levantadas todas as cotas de soleiras de portas da edificação em questão, com observação de possíveis desnivelamentos ou recalques da mesma. 


\section{MATERIAIS UTILIZADOS PARA A RECUPERAÇÃO ESTRUTURAL}

Para a condução da presente recuperação foram utilizados diversos materiais: i) Chapas de aço LCG (no encamisamento dos pilares foram utilizadas chapas de aço A 36 - laminador de chapa grossa - de $8 \mathrm{~mm}$, pois apresenta boa soldabilidade, devido as pequenas quantidades de carbono); ii) Argamassa de cal hidratada (a proporção do traço é definida de acordo com a finalidade e no caso é utilizada para o revestimento (proteção) das chapas de aço. Foram utilizados cal hidratada, areia fina no traço 1:3 com aditivo acrílico); iii) Argamassa de cal hidráulica (utilizada no traço de 1:3); iv) Adesivo acrílico (para aumentar a aderência das chapas de aço com os pilares); v) Cimento (o cimento utilizado foi o Portland de Alto Forno, por sua maior impermeabilidade e durabilidade, com também seu baixo teor de álcalis e de sulfatos); vi) Graute de injeção (foi adotada a calda de cal hidratada com aditivo hidráulico - pó de tijolo -, com traço inicial 1:0,5:2, sendo uma parte de cal para meia parte de pó de tijolo), e; vii) Barras chatas de aço (diâmetro de $1 / 2$ " soldadas para ajudar na fixação das chapas nos maciços, na largura de $5 \mathrm{~cm}$ ).

\subsection{Procedimentos de execução de recuperação estrutural}

Iniciando as ações referentes a recuperação propriamente dita, é relevante anotar que a experiência com casos semelhantes é de suma importância, uma vez que não se deve esquecer que a fonte mais segura para a pesquisa das técnicas construtivas aplicadas em uma determinada região, tem sido o estudo dos métodos aplicados nos remanescentes arquitetônicos do local alvo (Ribeiro, 2007).

\subsubsection{Recuperação dos pilares}

a) Alvenarias de Tijolos

Esse material era, até então, mais utilizado para o preenchimento de vãos em estruturas de madeira do tipo quadrado ou, para a execução de determinados elementos nas alvenarias de pedra de mão, tais como: cunhais ou como é o caso do Convento das Mercês, nos arcos de descarga sobre vãos.

\section{b) Escoramento}

Para a segurança estrutural e alívio significativo de cargas, na execução dos serviços foi utilizado um novo escoramento com reaproveitamento do existente (conforme a figura 4). A nova concepção elevou os escoramentos à parte superior da parede, alcançando as tesouras de cobertura, a fim de proporcionar uma redução ainda maior nas cargas atuantes na parede.

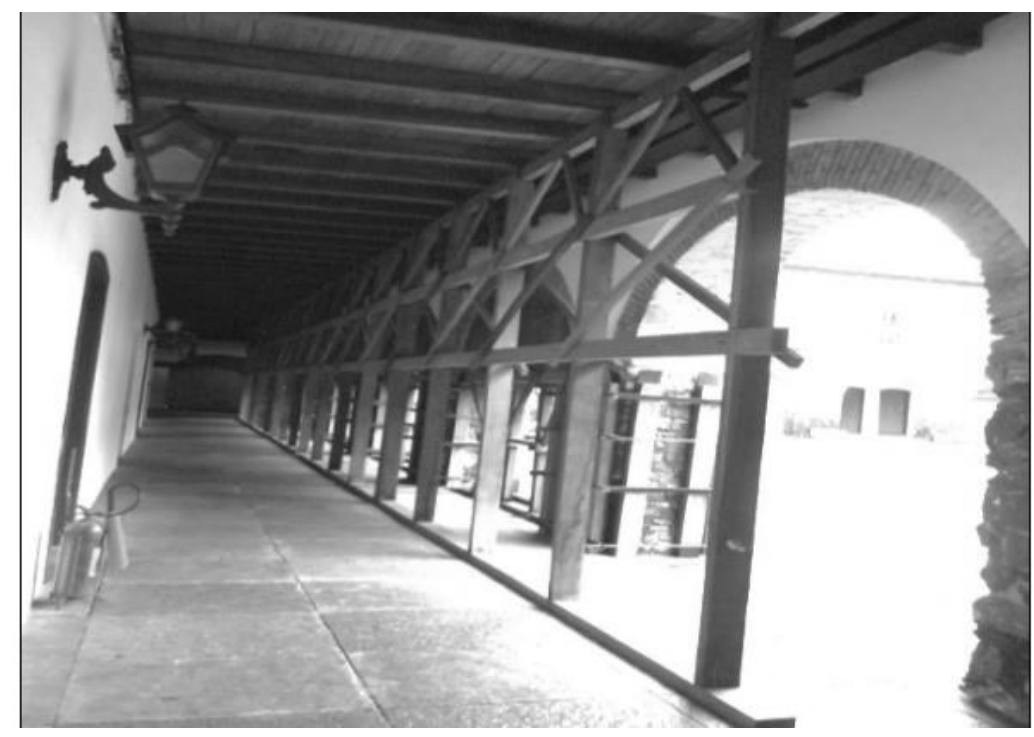

Figura 4 - Escoramento das paredes Fonte: O autor (2020). 
c) Recuperação dos pilares do Claustro

Os serviços de recuperação estrutural se iniciaram pela recuperação dos maciços dos pilares do claustro. Conforme o projeto de recuperação, os pilares seguiram ordenamento nos serviços, sendo executados do pilar em melhores condições estruturais para o de pior condição estrutural.

\subsubsection{Tratamento das desagregações}

Nesse tratamento, foram adotadas as seguintes ações: i) limpeza manual e com aspirador da região desagregada; ii) limpeza do pilar com água corrente, e; iii) aplicação de argamassa de cal hidratada na região afetada, o que fora feito com o maciço ainda úmido.

\subsubsection{Tratamento de trincas profundas}

Nesse processo, foram utilizados os seguintes procedimentos:

1. Na região afetada pela trinca foi colocado um novo embrechamento com uso de escassilhos;

2. Preenchimento das fraturas nas laterais com o auxílio de argamassa de cal hidráulica e aditivo hidráulico (pó de tijolo) e areia média;

3. Aplicação de injeção de calda de cal hidráulica com o uso de mangueiras plásticas.

A aplicação deve ocorrer em pontos distintos ao longo da fratura (separados entre si, aproximadamente, $25 \mathrm{~cm}$ ) e, em ambos os lados da parede (conforme a figura 5).

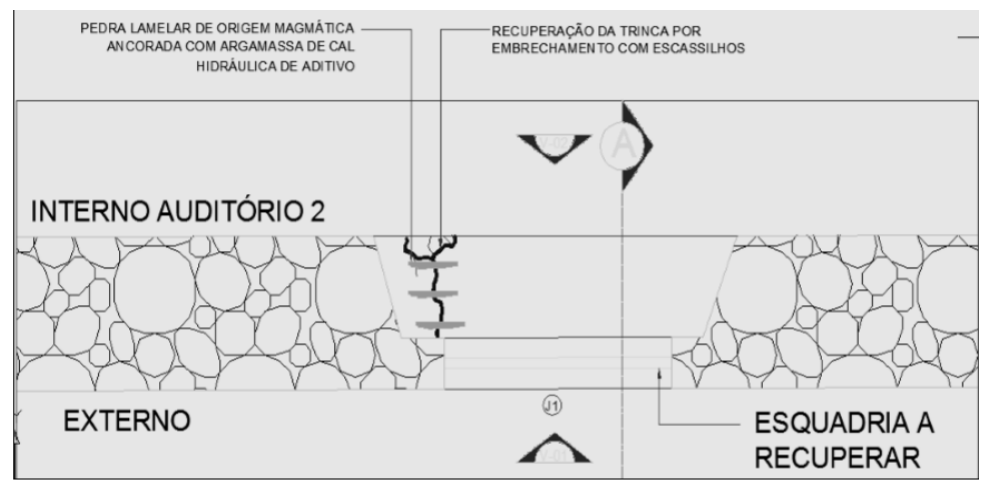

Figura 5 - Esquematização para tratamento de trincas profundas Fonte: o Autor (2020). 


\subsubsection{Injeção de calda (grauteamento)}

A técnica de consolidação de alvenarias por injeção (grauteamento) consistiu na implantação de caldas, por meio de furos previamente feitos nos paramentos exteriores das alvenarias, para completar os vazios interiores e/ou selagem de fissuras, modificando assim, as características físicas e mecânicas do material da alvenaria (conforme a figura 6).

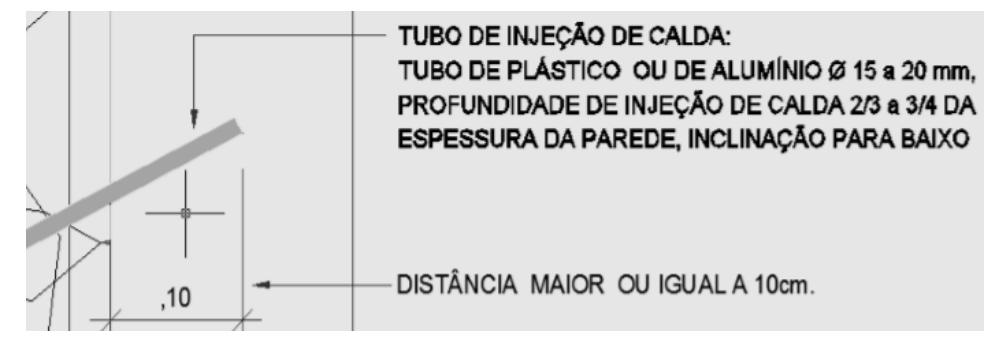

Figura 6 - Detalhe do tubo de injeção do grauteamento Fonte: O autor (2020).

O preparo do "graute" foi feito de forma mecanizada, a fim de garantir a homogeneidade e qualidade da mistura. A injeção foi efetuada por gravidade ou a baixa pressão $(0.1$ a $0.2 \mathrm{MPa})$, de modo a não provocar efeitos negativos na alvenaria existente. Esta técnica foi utilizada em caso de fraturas, desagregações e falta de integridade das paredes ou maciços de pedras.

\subsubsection{Encamisamento dos Pilares}

As placas metálicas deveriam estar limpas e isentas de óleos (conforme a figura 7), para a perfeita aderência dos materiais à base de cal que seriam aplicados.

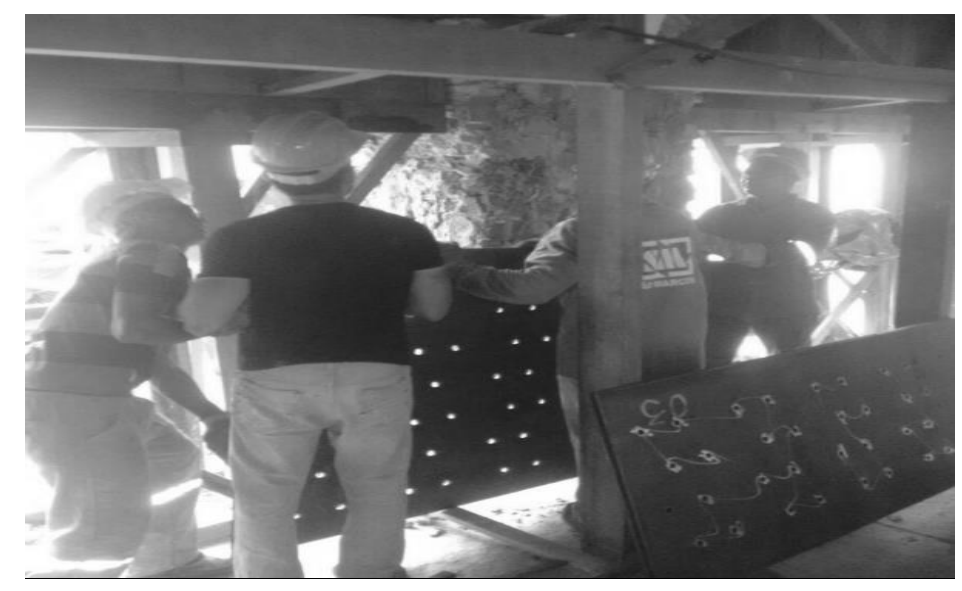

Figura 7 - Placas de aço para encamisamento

Fonte: O autor (2020). 
A folga entre as placas metálicas e as faces dos pilares deveriam ser as menores possíveis para manter o ajustamento perfeito das placas e a pouca utilização de calda de injeção, procedimento este, utilizado para reforço estrutural dos pilares.

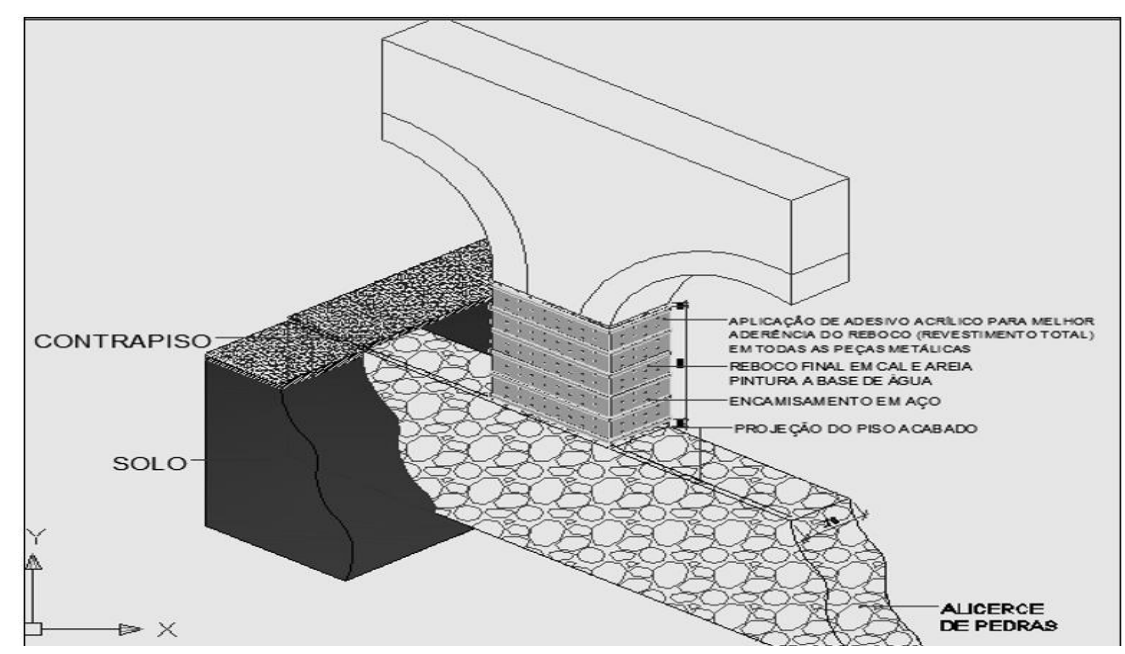

Figura 8 - Esquematização do encamisamento. Fonte: O autor (2020).

A figura 8 demonstra detalhe das barras chatas de aço utilizadas como cantoneiras para fixação das chapas de aço junto aos maciços.

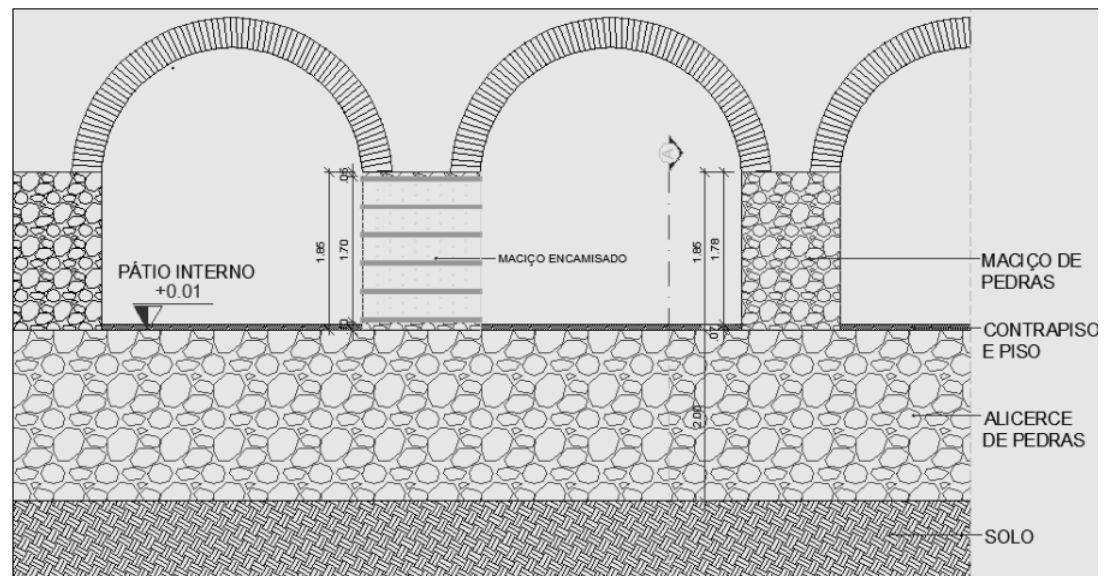

Figura 9 - Esquematização do encamisamento dos pilares (vista frontal) Fonte: O autor (2020).

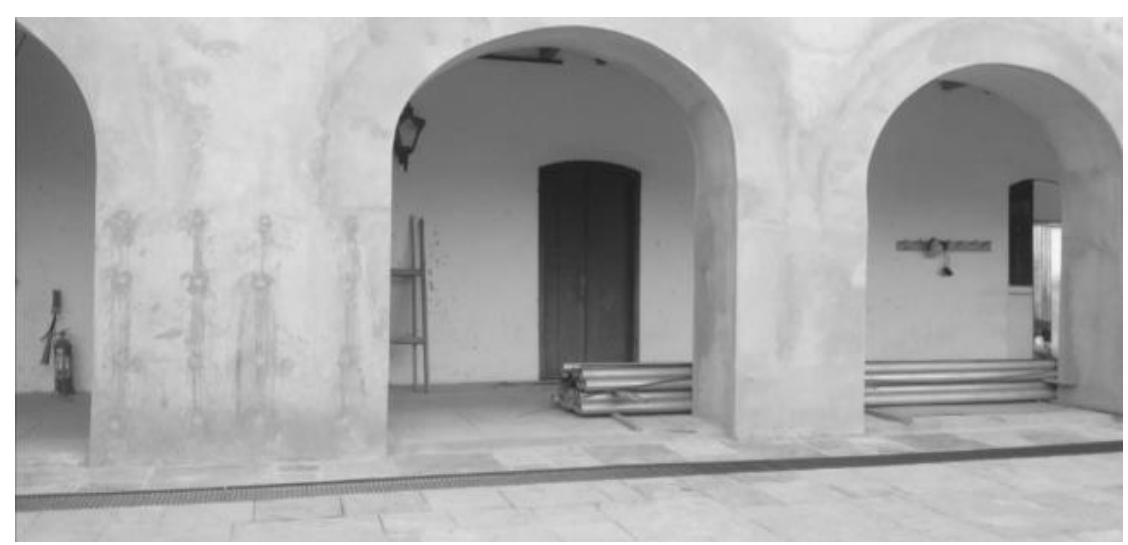

Figura 10 - Pilares após a recuperação estrutural Fonte: O autor (2020). 


\section{СВРAT 2020

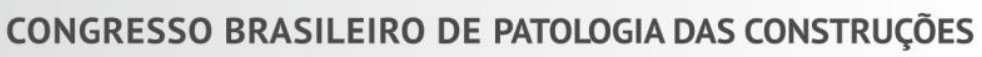 \\ DE 15 A 17 DE ABRIL | FORTALEZA - CE \\ ISBN 978-65-86819-05-2

As figuras 8 e 9 mostram o esquema do encamisamento dos pilares direcionados para a Rua da Estrela, já na Figura 10, ilustra-se a obra finalizada após a recuperação dos pilares.

\subsubsection{Reconstituição de argamassas}

A aplicação de reboco foi necessária para majorar a proteção contra as intempéries, sendo que tal substrato deveria ser preparados de forma a se tornar permeável a base de argamassa de cal e areia, com um traço 1:2 ou 1:3, sendo a areia média e fina lavada e sem a presença de sais e matéria orgânica, preparada mecanicamente para garantir a homogeneidade e qualidade da mistura.

As pinturas foram executadas com tintas a base de água para permitir que os poros das argamassas se apresentem livres para a evaporação de água das paredes. A argamassa de reconstituição do piso mostrou-se semelhante à do restante dos vãos da sala. Portanto, levando em consideração tal descrição, tem-se nas figuras 10 e 11 como os pilares ficaram após todo este processo de recuperação.

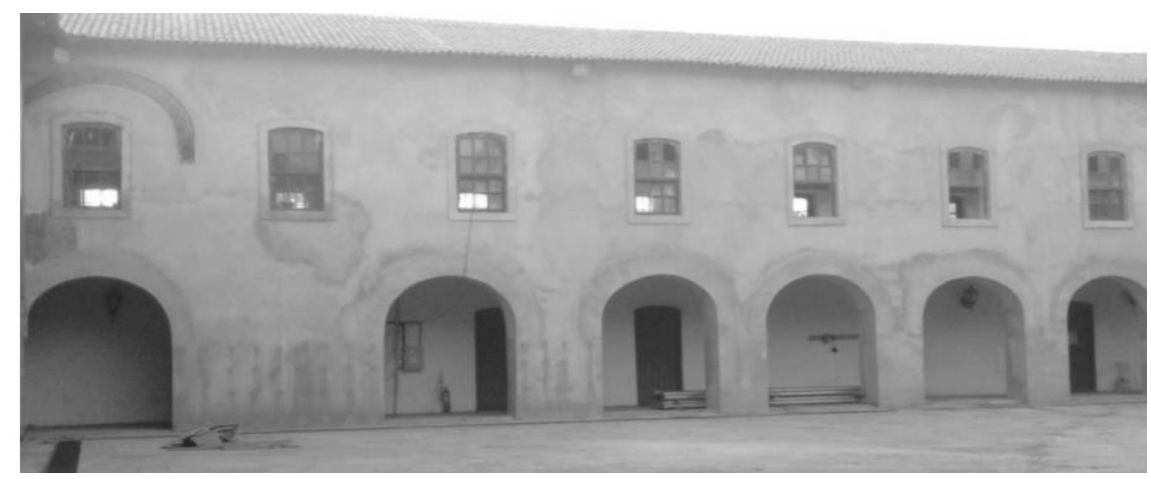

Figura 11 - Pilares recuperados do claustro

Fonte: O autor (2020). 


\section{CONCLUSÃO}

O imóvel, objeto do presente estudo, apresentava anomalias que se não tratadas certamente, levariam ao longo do tempo, a deterioração progressiva da edificação. A fim de evitar tal realidade, foram adotadas medidas corretivas que impediram a degradação da edificação do imóvel objeto da intervenção realizada.

Na edificação objeto de estudo foi elaborado projeto de ações corretivas, baseado em análise de solos, sistema hidráulico, levantamento topográfico e avaliação das necessidades e características do local; pois a edificação encontrase em um ambiente agressivo para a sua estrutura constituída basicamente de argila siltosa e pedras lamelares.

O terreno foi alvo de estudos de prospecção, ensaios e testes. Em tal etapa, identificou-se deficiência de drenagem das águas provindas das chuvas.

Nos pilares, detectou-se facilmente paredes com vãos em seu interior, problema este contornado com o auxílio de tubos metálicos de injeção de 'calda' ou 'grout'. Após este procedimento, foi utilizada a técnica de encamisamento para contenção de perda de argamassa de argila siltosa e pedras lamelares, com chapas de aço A36 de 5/16" para reforço estrutural dos pilares gravemente deteriorados por intempéries, águas de lavagem e reverberação. Este método foi escolhido por não agredir as instalações históricas tombadas pelo Instituto do Patrimônio Histórico e Artístico Nacional (IPHAN).

As consideráveis melhorias observadas após a execução dos procedimentos acima citados já podem ser verificadas na atualidade, no prédio da Fundação da Memória Republicana Brasileira. Convém ressaltar que o objetivo proposto com a execução destes estudos e procedimentos foi alcançado, tendo em vista que para a intervenção realizada utilizou-se também de informações e dados coletados a partir das observações "in loco", visitas técnicas aos locais e prospecções, obedecendo os procedimentos técnicos adequados ao objeto de análise, de modo a protegê-lo de manifestações patológicas futuras e desabamentos. 


\section{REFERÊNCIAS}

ABNT - Associação Brasileira de Normas Técnicas. NBR 14653-7: bens de patrimônio histórico e artístico: Rio de Janeiro, 2009.

ABNT - Associação Brasileira de Normas Técnicas. NBR 6118: projetos de estrutura de concreto - procedimento: Rio de Janeiro, 2014.

BONIN, L. C. Massa crítica pela qualidade. Téchne - Revista de Tecnologia da Construção, São Paulo, ano 8, p.68, jul./ago. 1999.

DUARTE, R. B. Fissuras em Alvenaria: causas principais, medidas preventivas e técnicas de recuperação. Porto Alegre: CIENTEC, 1988.

ELDRIDGE, H.J., Construcción, defectus comunes. Barcelona: Gustavo Gili, 1982.

GANDELMAN, S. R. D. Acervos culturais e acesso ao público - questões jurídicas. 154f. Dissertação (Mestrado em Bens Culturais e Projetos) - Centro de Pesquisa e Documentação de História Contemporânea do Brasil - CPDOC, Rio de Janeiro, 2006.

GOMIDE, Tito Lívio; FAGUNDES NETO, Jerônimo; GULLO, Marco Antônio, Engenharia diagnóstica em Edificações, São Paulo, Pini, 2009.

MEIRELES, M. Mário. Fundação Memorial José Sarney, Convento das Mercês, São Luís, 1991.

PÁDUA, R. C. Pilares de concreto armado reforçados por meio de encamisamento. REEC - Revista Eletrônica de

Engenharia Civil, v. 5, p.75-86, 2012. Disponível em: <https://www.revistas.ufg.br/reec/article/download /20933/12295>. Acesso em: 25 mai. 2019.

RANSOM, W. H. Bulding failures diagnose and avoidance. 2. ed. London: E. \& F. N. spon, 1987.

RIBEIRO, N. P. Revista Brasileira de Arqueometria, Restauração e Conservação, Vitória, v. 1, n. 5, p.281, 2007.

SILVA, L. M. B. Desenvolvimento de um especialista para diagnóstico de fissuras para concreto aramado. 1996. Dissertação (Mestrado em Engenharia) - Curso de Pós Graduação em Engenharia Civil, Universidade Federal do Rio Grande do Sul, Porto Alegre. 